\title{
HIV Protease Inhibitors Inhibit FACE1/ZMPSTE24: A Mechanism for Acquired Lipodystrophy in Patients on Highly Active Anti Retroviral Therapy?
}

Chris. N. Goulbourne* and David. J. Vaux ${ }^{*+}$

Author Affiliation: "Sir William Dunn School of Pathology, University of Oxford, South Parks Road, Oxford, OX1 3RE.

${ }^{\dagger}$ To whom correspondence may be addressed. E-mail david.vaux@path.ox.ac.uk

Key Words: Nuclear envelope, Prelamin A, HIV protease inhibitor, Zmpste24, acquired lipodystrophy

\section{ABSTRACT}

HIV protease inhibitors have proved to be of great benefit for the millions of people suffering from AIDS. However, one of the side effects of this component of combined Highly Active Anti-

Retroviral Therapy is lipodystrophy, which affects a large number of the patients taking this class of drug. It has been shown that many of these protease inhibitors inhibit the ZMPSTE24 enzyme responsible for removing the farnesylated tail of prelamin A, which is a nuclear lamina component that has been implicated in some of the nuclear laminopathies. Build up of this protein somehow leads to acquired lipodystrophy, possibly through its interaction with a transcription factor called SREBP-1. The downstream effect of this is altered fatty acid metabolism and sterol synthesis, which may cause lipodystrophy in patients. The build up of this protein also appears to have morphological consequences on the nucleus and we reveal by dual axis electron tomography a complex nucleoplasmic reticulum that forms after HIV protease inhibitor treatment as a result of acute farnesylated prelamin A accumulation. A greater understanding of the molecular 
mechanisms leading to lipodystrophy will hopefully facilitate the design of improved HIV protease inhibitors that do not cause this debilitating side effect.

\section{Main Article}

Nuclear laminopathies are a group of diseases that result from mutations in genes that encode components of the nuclear lamina and associated proteins [1-18]. These moderately rare diseases can be separated into four major classes, which are diseases of striated muscle, peripheral neuropathy, lipodystrophy syndromes and multisystem disorders that can resemble accelerated aging. The LMNA gene encodes two lamina proteins (lamins $A$ and $C$ ) via differential splicing [19]. Mutations in the LMNA gene can cause various laminopathies with different degrees of severity based on the position of the mutation in the gene. Lamin A is initially generated as farnesylated prelamin A, which undergoes a series of post translational modifications including endoproteolytic cleavages that ultimately results in removal of the Cterminal farnesylated tail [20-22]. The most frequent de novo mutation in LMNA that has been associated with the rare accelerated aging disorder, Hutchinson-Gilford Progeria Syndrome (HGPS), activates a cryptic splice site leading to the generation of an internally truncated but persistently farnesylated prelamin A called progerin [14]. The reason for the retention of the farnesylated $\mathrm{C}$-terminus is that the mutation causes the removal of the second cleavage site for the enzyme FACE1 (ZMPSTE24 in mice) [23]. FACE1 is an integral membrane zinc metalloproteinase found in both the nuclear and endoplasmic reticulum (ER) membranes [24, 25]. Mouse models of HGPS, in which the ZMPSTE24 enzyme is knocked out (Zmpste24 ${ }^{-1-}$ ), show a phenotype that is similar to many of the clinical features displayed in progeria such as osteoporosis, alopecia and lipodystrophy [26].

FACE 1 is clearly an important enzyme for the correct maturation of lamin A and normal functioning of the nucleus [24]. Zmpste24 ${ }^{-/-}$mouse models generate persistently farnesylated prelamin A leading to severely dysmorphic nuclei [27], an alteration of expression in genes that regulate cell cycle progression [28] and a systemic metabolic response involving autophagy induction [29]. 
Within the last ten years it has been reported that certain drugs seem to inhibit the maturation of lamin A, resulting in the accumulation of farnesylated prelamin A. These include the HIV protease inhibitors (HIV-Pl's) that are used to treat some of the 33.2 million people in the world living with AIDS as part of Highly Active Anti Retroviral Therapy (HAART) [30-35]. HIV-PI's are designed to inhibit the HIV aspartyl protease from generating structural proteins for the virus. However, some HIV-PI's also inhibit FACE1/ZMPSTE24; this effect was initially characterised by measuring decreased specific activity of an ortholog of ZMPSTE24 (STE24P from yeast) upon HIV-PI treatment [34]. At physiologically relevant concentrations the HIV-PI's indinavir, nelfinavir, tipranavir, lopinavir and atazanavir all cause the accumulation of farnesylated prelamin A around the nuclear envelope [30-35] leading to dysmorphic nuclei similar to nuclei from HGPS fibroblasts [30]. The abundance of mitochondrial reactive oxygen species is elevated after treatment with these HIV-PIs, which may contribute to cells reaching an earlier senescent state and a greater degree of DNA damage, which is an important mechanism leading to premature ageing in HGPS [30].

Acquired lipodystrophy, as a result of HAART, was first reported over ten years ago. It is characterized by the abnormal redistribution of fat tissue around the body, which may lead to both lipohypertrophy and lipoatrophy within 10 months of beginning drug therapy [36] and has $25-75 \%$ prevalence among HAART patients [37]. Lipohypertrophy is caused by the accumulation of fat in some parts of the body, such as the belly, upper torso and the back of the neck, leading to the characteristic "buffalo hump" [38] Lipoatrophy is due to fat loss in other regions of the body such as the face, buttocks and arms [39]. Psychologically the symptoms can lead to anxiety and depression due to decreased self esteem, sexual relation problems and general dissatisfaction with body image [40-42]. The iatrogenic consequences of HAART leads many individuals to end up abandoning treatment altogether [43]. The mechanism by which HIV-PI mediated accumulation of farnesylated prelamin A leads to this acquired lipodystrophy syndrome remains incompletely understood.

Sterol Regulatory Element Binding Protein (SREBP) is a transcription factor that exists in three isoforms (SREBP-1a, SREBP-1c and SREBP-2). SREBP-1a is held in the ER and nuclear 
membranes, before being activated by periods of low sterol levels in the cell and the mature $\mathrm{N}$ terminus eventually translocates to the nucleus, where it activates genes involved in fatty acid metabolism and adipocyte differentiation [44, 45]. Co-immunoprecipitation has shown that prelamin A that contains the C-terminal fragment normally removed by ZMPSTE24 interacts with SREBP-1a [46]. Further processing to mature lamin A resulted in no interaction with the SREBP1a transcription factor [46]. The presence of a farnesylated tail does not seem to make a difference to the interaction between prelamin A and SREBP-1a as immunofluorescence microscopy has shown a nuclear rim staining of the active SREBP-1a in HEK293 cells transfected with a mutated $\mathrm{C} 661 \mathrm{M}$ prelamin A construct (generates unfarnesylated prelamin A) or a mutated L647R prelamin A construct (produces farnesylated prelamin A), rather than in the control situation where it had a more diffuse intranuclear distribution [46]. As HIV-PI treatment also results in the retention of a farnesylated tail on prelamin A it may offer a possible mechanism for the acquired lipodystrophy experienced in over $40 \%$ of AIDS sufferers on HARRT (Fig 1).

There is currently no treatment for the side effect, though some pharmaceutical companies are developing compounds to tackle this disease e.g. Tesamorelin is a growth hormone, produced by Theratechnologies, which reduced fat levels by twenty percent [47]. Despite the production of farnesylated prelamin A by certain HIV PI's some of the newer generation of HIV Pl's have been found not to cause this unprocessed protein to accumulate. Darunavir has been shown not to inhibit Ste24p and biochemical data revealed no farnesylated prelamin A accumulation of concentrations up to $80 \mu \mathrm{M}$ [33]. This obviously offers hope to AIDS sufferers and provides a new approach into the development of these therapeutics.

The research conducted in our laboratory has offered new insights into how these drugs are affecting the morphology of the nucleus by using dual axis electron tomography. We have shown that acute administration of an older generation of HIV PI, to mouse embryonic fibroblasts, generated a complex nucleoplasmic reticulum (NR) inside the nuclei (Fig 2). The NR in these cells is not the more common double-membraned invagination of the whole nuclear envelope but is rather composed of single-membraned cisternae containing embedded nuclear pore complexes (NPCs) with a nucleoplasmic to nucleoplasmic orientation. These structures were 
revealed by initially observing them from transmission electron microscopy images. To get a greater appreciation of their 3D structure dual axis electron tomography was used. A 250nm thick section was collected of the treated cells and $10 \mathrm{~nm}$ colloidal gold particles were applied to each surface, to act as fiducial markers for subsequent image analysis. Dual axis tilt series from $-65^{\circ}$ to $+65^{\circ}$ at $1^{\circ}$ intervals were obtained and the tomographic reconstruction and modelling was performed using the IMOD software package.

It has been previously reported that the C-terminus of farnesylated prelamin A has been found to interact with the nucleoporin nup53 [48]. In HIV-PI treated cells it could therefore be envisaged that the inhibition of ZMPSTE24 causes farnesylated prelamin A to build up and the unprocessed protein may then interact with the nuclear membrane as well as other components of the nuclear architecture. This may lead to a highly convoluted and disorganized nuclear membrane. If NPC's are ending up inside the nucleus and the NPC number is reduced along the nuclear membrane during interphase, then they cannot be fulfilling their role of transporting molecules across the nuclear envelope, which may add to the pathological symptoms observed inside cells that accumulate farnesylated prelamin A. Efforts are now underway to distinguish whether farnesylation is essential for this unusual NR phenotype, or whether accumulation of unfarnesylated prelamin $A$ is sufficient.

\section{References}

[1]. Chen, L., Lee, L., Kudlow, B.A., Dos Santos, H.G., Sletvold, O., Shafeghati, Y., Botha, E.G., Garg, E., Hanson, N.B., Martin, G.M., Mian, I.S., Kennedy, B.K. and Oshima, J. (2003) LMNA mutations in atypical Werner's syndrome. Lancet. 362, 440445

[2]. Hegele, R.A., Cao, H., Liu, D.M., Costain, G.A., Charlton-Menys, V., Rodger, N.W. and Durrington, P.N. (2006) Sequencing of the reannotated LMNB2 gene reveals novel mutations in patients with acquired partial lipodystrophy. Am. J. Hum. Genet. 79, 383389

[3]. Hellemans, J., Preobrazhenska, O., Willaert, A., Debeer, P., Verdonk, P.C.M., Costa, T., Janssens, K., Menten, B., Van Roy, N., Vermeulen, S.J.T., Savarirayan, R., Van Hul, W., Vanhoenacker, F., Huylebroeck, D., De Paepe, A., Naeyaert, J.M., Vandesompele, J., 
Speleman, F., Verschueren, K., Coucke, P.J. and Mortier, G.R. (2004) Loss-of-function mutations in LEMD3 result in osteopoikilosis, Buschke-Ollendorff syndrome and melorheostosis. Nature Genet. 36, 1213-1218.

[4]. Charniot, J.C., Pascal, C., Bouchier, C., Sebillon, P., Salama, J., Duboscq-Bidot, L., Peuchmaurd, M., Desnos, M., Artigou, J.Y. and Komajda, M. (2003) Functional consequences of an LMNA mutation associated with a new cardiac and non-cardiac phenotype. Hum. Mutat. 21, 473-481.

[5]. De Sandre-Giovannoli, A., Chaouch, M., Kozlov, S., Vallat, J.M., Tazir, M., Kassouri, N., Szepetowski, P., Hammadouche, T., Vandenberghe, A., Stewart, C.L., Grid, D. and Levy, N. (2002) Homozygous defects in LMNA, encoding lamin A/C nuclear-envelope proteins, cause autosomal recessive axonal neuropathy in human (Charcot-Marie-Tooth disorder type 2) and mouse. Am. J. Hum. Genet. 70, 726-736.

[6]. Manilal, S., Nguyen, T.M., Sewry, C.A. and Morris, G.E. (1996) The EmeryDreifuss muscular dystrophy protein, emerin, is a nuclear membrane protein. Hum. Mol. Genet. 5, 801-808.

[7]. Bonne, G., Di Barletta, M.R., Varnous, S., Becane, H.M., Hammouda, E.H., Merlini, L., Muntoni, F., Greenberg, C.R., Gary, F., Urtizberea, J.A., Duboc, D., Fardeau, M., Toniolo, D. and Schwartz, K. (1999) Mutations in the gene encoding lamin A/C cause autosomal dominant Emery-Dreifuss muscular dystrophy. Nature Genet. 21, 285-288.

[8]. Raffaele di Barletta, M., Ricci, E., Galluzzi, G., Tonali, P., Mora, M., Morandi, L., Romorini, A., Voit, T., Orstavik, K.H., Merlini, L., Trevisan, C., Biancalana, V., Housmanowa-Petrusewicz, I., Bione, S., Ricotti, R., Schwartz, K., Bonne, G. and Toniolo, D. (2000) Different mutations in the LMNA gene cause autosomal dominant and autosomal recessive Emery-Dreifuss muscular dystrophy. Am. J. Hum. Genet. 66, 1407-1412.

[9]. Cao, H. and Hegele, R.A. (2002) Nuclear lamin A/C R482Q mutation in Canadian kindreds with Dunnigan-type familial partial lipodystrophy. Hum. Molec. Genet. 9, 109112.

[10]. Waterham, H.R., Koster, J., Mooyer, P., van Noort, G., Kelley, R.I., Wilcox, W.R., Wanders, R.J.A., Hennekam, R.C.M. and Oosterwijk, J.C. (2003) Autosomal recessive HEM/Greenberg skeletal dysplasia is caused by 3-beta-hydroxysterol delta(14)-reductase deficiency due to mutations in the lamin B receptor gene. Am. J. Hum. Genet. 72, 10131017.

[11]. Muchir, A., Bonne, G., van der Kooi, A.J., van Meegen, M., Baas, F., Bolhuis, P.A., de Visser, M. and Schwartz, K. (2000) Identification of mutations in the gene encoding lamins $\mathrm{A} / \mathrm{C}$ in autosomal dominant limb girdle muscular dystrophy with atrioventricular conduction disturbances (LGMD1B). Hum. Molec. Genet. 9, 1453-1459. 
[12]. Caux, F., Dubosclard, E., Lascols, O., Buendia, B., Chazouilleres, O., Cohen, A., Courvalin, J.C., Laroche, L., Capeau, J., Vigouroux, C. and Christin-Maitre, S. (2003) A new clinical condition linked to a novel mutation in lamins $\mathrm{A}$ and $\mathrm{C}$ with generalized lipoatrophy, insulin-resistant diabetes, disseminated leukomelanodermic papules, liver steatosis, and cardiomyopathy. J. Clin. Endocr. Metab. 88, 1006-1013.

[13]. Novelli, G., Muchir, A., Sangiuolo, F., Helbling-Leclerc, A., D'Apice, M.R., Massart, C., Capon, F., Sbraccia, P., Federici, M., Lauro, R., Tudisco, C., Pallotta, R., Scarano, G., Dallapiccola, B., Merlini, L. and Bonne, G. (2002) Mandibuloacral dysplasia is caused by a mutation in LMNA-encoding lamin A/C. Am. J. Hum. Genet. 71, 426-431.

[14]. Eriksson, M., Brown, W.T., Gordon, L.B., Glynn, M.W., Singer, J., Scott, L., Erdos, M.R., Robbins, C.M., Moses, T.Y., Berglund, P., Dutra, A., Pak, E., Durkin, S., Csoka, A.B., Boehnke, M., Glover, T.W. and Collins, F.S. (2003) Recurrent de novo point mutations in lamin A cause Hutchinson-Gilford progeria syndrome. Nature 423, 293298.

[15]. Agarwal, A.K., Fryns, J.P., Auchus, R.J. and Garg, A. (2003) Zinc metalloproteinase, ZMPSTE24, is mutated in mandibuloacral dysplasia. Hum. Molec. Genet. 12, 1995-2001.

[16]. Hoffmann, K., Dreger, C.K., Olins, A.L., Olins, D.E., Shultz, L.D., Lucke, B., Karl, H., Kaps, R., Muller, D., Vaya, A., Aznar, J., Ware, R.E., Cruz, N.S., Lindner, T.H., Herrmann, H., Reis, A. and Sperling, K. (2002) Mutations in the gene encoding the lamin $\mathrm{B}$ receptor produce an altered nuclear morphology in granulocytes (Pelger-Huet anomaly). Nature Genet. 31, 410-414.

[17]. Padiath, Q.S., Saigoh, K., Schiffmann, R., Asahara, H., Yamada, T., Koeppen, A., Hogan, K., Ptacek, L.J. and Fu, Y.H. (2006) Lamin B1 duplications cause autosomal dominant leukodystrophy. Nature Genet. 38, 1114-1123.

[18]. Navarro, C.L., De Sandre-Giovannoli, A., Bernard, R., Boccaccio, I., Boyer, A., Genevieve, D., Hadj-Rabia, S., Gaudy-Marqueste, C., Smitt, H.S., Vabres, P., Faivre, L., Verloes, A., Van Essen, T., Flori, E., Hennekam, R., Beemer, F.A., Laurent, N., Le Merrer, M., Cau, P. and Levy, N. (2004) Lamin A and ZMPSTE24 (FACE-1) defects cause nuclear disorganization and identify restrictive dermopathy as a lethal neonatal laminopathy. Hum. Molec. Genet. 13, 2493-2503.

[19]. Machiels, B.M., Zorenc, A.H., Endert, J.M., Kuijpers, H.J., van Eys, G.J., Ramaekers, F.C. and Broers, J.L. (1996) An alternative splicing product of the lamin A/C gene lacks exon 10. Journal of Biological Chemistry. 271, 9249-9253.

[20]. Beck, L.A., Hosick, T. J. and Sinensky, M. (1990) Isoprenylation is required for the processing of the lamin A precursor. J. Cell Biol. 110, 1489-1499. 
[21]. Corrigan, D.P., Kuszczak, D., Rusinol, A.E., Thewke, D.P., Hrycyna, C.A., Michaelis, S. and Sinensky, M.S. (2005) Prelamin A endoproteolytic processing in vitro by recombinant Zmpste24. Biochem. J. 387, 129-138.

[22]. Weber, K., Plessmann, U. and Traub, P. (1989) Maturation of nuclear lamin A involves a specific carboxy-terminal trimming, which removes the polyisoprenylation site from the precursor; implications for the structure of the nuclear lamina. FEBS Lett. 257, 411-414.

[23]. Mounkes, L.C., Kozlov, S., Hernandez, L., Sullivan, T. and Stewart, C.L. (2003) A progeroid syndrome in mice is caused by defects in A-type lamins. Nature. 423, 298-301.

[24]. Freije, J.M., Blay, P., Pendás, A.M., Cadiñanos, J., Crespo, P., López-Otín, C. (1999) Identification and chromosomal location of two human genes encoding enzymes potentially involved in proteolytic maturation of farnesylated proteins. Genomics. 58, 270-280.

[25]. Gruber, J., Lampe, T., Osborn, M., Weber, K. (2005) RNAi of FACE1 protease results in growth inhibition of human cells expressing lamin A: implications for Hutchinson-Gilford progeria syndrome. Journal of Cell Science. 118, 689-696.

[26]. Bergo, M.O., Gavino, B., Ross, J., Schmidt, W.K., Hong, C., Kendall, L.V., Mohr, A., Meta, M., Genant, H., Jiang, Y., Wisner, E.R., Van Bruggen, N., Carano, R.A., Michaelis, S., Griffey, S.M., Young, S.G. (2002). Zmpste24 deficiency in mice causes spontaneous bone fractures, muscle weakness, and a prelamin A processing defect. Proc Natl Acad Sci U S A. 99, 13049-13054.

[27]. Fong, L.G., Ng, J.K., Meta, M., Cote, N., Yang, S.H., Stewart, C.L., Sullivan, T., Burghardt, A., Majumdar, S., Reue, K., Bergo, M.O. and Young, S.G. (2004). Heterozygosity for Lmna deficiency eliminates the progeria-like phenotypes in Zmpste24-deficient mice. Proc Natl Acad Sci U S A. 101, 18111-18116.

[28]. Varela, I., Cadiñanos, J., Pendás, A.M., Gutiérrez-Fernández, A., Folgueras, A.R., Sánchez, L.M., Zhou, Z., Rodríguez, F.J., Stewart, C.L., Vega, J.A., Tryggvason, K., Freije, J.M., López-Otín, C. (2005). Accelerated ageing in mice deficient in Zmpste24 protease is linked to p53 signalling activation. Nature. 437, 564-568.

[29]. Mariño, G., Ugalde, A.P., Salvador-Montoliu, N., Varela, I., Quirós, P.M., Cadiñanos, J., van der Pluijm, I., Freije, J.M., López-Otín, C. (2008) Premature aging in mice activates a systemic metabolic response involving autophagy induction. Human Molecular Genetics. 17, 2196-2211.

[30]. Caron, M., Auclair, M., Donadille, B., Béréziat, V., Guerci, B., Laville, M., Narbonne, H., Bodemer, C., Lascols, O., Capeau, J. and Vigouroux, C. (2007) Human lipodystrophies linked to mutations in A-type lamins and to HIV protease inhibitor 
therapy are both associated with prelamin A accumulation, oxidative stress and premature cellular senescence. Cell Death and Differentiation. 14, 1759-1767.

[31]. Coffinier, C., Hudon, S.E., Farber, E.A., Chang, S.Y., Hrycyna, C.A., Young, S.G. and Fong, L.G. (2007). HIV protease inhibitors block the zinc metalloproteinase ZMPSTE24 and lead to an accumulation of prelamin A in cells. Proc Natl Acad Sci U S A. 104, 13432-13437.

[32]. Clarke, S. G. (2007). HIV protease inhibitors and nuclear lamin processing: getting the right bells and whistles. Proc Natl Acad Sci U S A. 104, 13857-13858.

[33]. Coffinier, C., Hudon, S.E., Lee, R., Farber, E.A., Nobumori, C., Miner, J.H., Andres, D.A., Spielmann, H.P., Hrycyna, C.A., Fong, L.G. and Young, S.G. (2008) A potent HIV protease inhibitor, darunavir, does not inhibit ZMPSTE24 or lead to an accumulation of farnesyl-prelamin A in cells. Journal of Biological Chemistry. 283, 9797-9804.

[34]. Hudon, S.E., Coffinier, C., Michaelis, S., Fong, L.G., Young, S.G. and Hrycyna, C.A. (2008) HIV-protease inhibitors block the enzymatic activity of purified Ste24p. Biochemical and Biophysical Research Communications._374, 365-368.

[35]. Saillan-Barreau, C., Tabbakh, O., Chavoin, J.P., Casteilla, L. and Pénicaud, L. (2008) Drug-specific effect of nelfinavir and stavudine on primary culture of human preadipocytes. J Acquir Immune Defic Syndr. 48, 20-25.

[36]. Carr, A. (2000) HIV protease inhibitor-related lipodystrophy syndrome. Clinical Infectious Diseases. 30 (Suppl. 2), S135-S142.

[37]. Vigouroux, C., Maachi, M., Nguyên, T.H., Coussieu, C., Gharakhanian, S., Funahashi, T., Matsuzawa, Y., Shimomura, I., Rozenbaum, W., Capeau, J. and Bastard, J.P. (2003) Serum adipocytokines are related to lipodystrophy and metabolic disorders in HIV-infected men under antiretroviral therapy. AIDS. 17, 1503-1511.

[38]. Sharma, D. and Bitterly, T.J. (2008) Buffalo hump in HIV patients: surgical management with liposuction. J Plast Reconstr Aesthet Surg. doi:10.1016/j.bjps.2007.10.086.

[39]. Rajagopalan, R., Laitinen, D. and Dietz, B. (2008) Impact of lipoatrophy on quality of life in HIV patients receiving anti-retroviral therapy. AIDS care. 20, 1197-1201.

[40]. Paton, N.I., Earnest, A., Ng, Y.M., Karim, F. and Aboulhab, J. (2002)

Lipodystrophy in a cohort of human immunodeficiency virus infected Asian patient: prevalence, associated factors, and psychological impact. Clinical Infectious Diseases. 35, 1244-1249. 
[41]. Collins, E., Wagner, C. and Walmsley, S. (2000) Psychosocial impact of the lipodystrophy syndrome in HIV infection. AIDS Read. 10, 546-550.

[42]. Power, R., Tate, H.L., McGill, S.M. and Taylor, C. (2003) A qualitative study of the psychosocial implications of lipodystrophy syndrome on HIV positive individuals. Sexually Transmitted Infections. 79, 137-141.

[43]. Tate, H. and George, R. (2001) The effect of weight loss on body image in HIV positive gay men. AIDS Care. 13, 163-169.

[44]. Wang, X., Sato, R., Brown, M.S., Hua, X. and Goldstein, J.L. (1994) SREBP-1, a membrane-bound transcription factor released by sterol-regulated proteolysis. Cell. 77, $17-19$.

[45]. Tontonoz, P., Kim, J.B., Graves, R.A. and Spiegelman, B.M. (1993) ADD1: a novel helix-loop-helix transcription factor associated with adipocyte determination and differentiation. Molecular Cell Biology. 13, 4753-4759.

[46] Capanni, C., Mattioli, E., Columbaro, M., Lucarelli, E., Parnaik, V.K., Novelli, G., Wehnert, M., Cenni, V., Maraldi, N.M., Squarzoni, S. and Lattanzi, G. (2005) Altered pre-lamin A processing is a common mechanism leading to lipodystrophy. Hum Mol Genet. 14, 1489-1502.

[47]. Falutz, J., Allas, S., Mamputu, J.C., Potvin, D., Kotler, D., Somero, M., Berger, D., Brown, S., Richmond, G., Fessel, J., Turner, R. and Grinspoon, S. (2008) Long-term safety and effects of tesamorelin, a growth hormone-releasing factor analogue, in HIV patients with abdominal fat accumulation. AIDS. 22, 1719-1728.

[48]. Pan, Y., Garg, A. and Agarwal, A.K. (2007) Mislocalization of prelamin A Tyr646Phe mutant to the nuclear pore complex in human embryonic kidney 293 cells. Biochem Biophys Res Commun.. 355, 78-84. 


\section{Figure Legends}

Fig 1 (a). Schematic of the normal situation within a cell in which during low sterol concentrations the active form of SREBP-1a can move through the NPC and activate target genes. (b). When farnesylated prelamin A build up occurs, as a result of acute ZMPSTE24 inhibition, the retained farnesylated tail (pink line) is believed to interact with the membrane resulting in the production of a highly dysmorphic nucleus and the development of a complex NR. Additionally SREBP-1a has been shown to be retained at the nuclear envelope, after farnesylated prelamin A accumulation, preventing activation of target genes involved in adipocyte differentiation and fatty acid metabolism, which may be a possible mechanism for the acquired lipodystrophy in patients on HAART.

Fig 2. (a). Dual axis electron tomography revealed invaginations inside the nucleus that appear to contain NPCs with a nucleoplasmic to nucleoplasmic orientation. The Imod software enables users to draw boundaries around structures, within the tomogram, allowing a 3D model to be generated. The colour key is as follows; brown marks the cell membrane (CM), purple is nuclear membrane (NM) and red labels the nucleoplasmic reticulum (NR) membrane. (b) By using modelling software a greater appreciation could be achieved of the structures within the tomogram and indicated that the NPC's in the NR had similar dimensions to those in the nuclear membrane. 
Figure 1

(a)

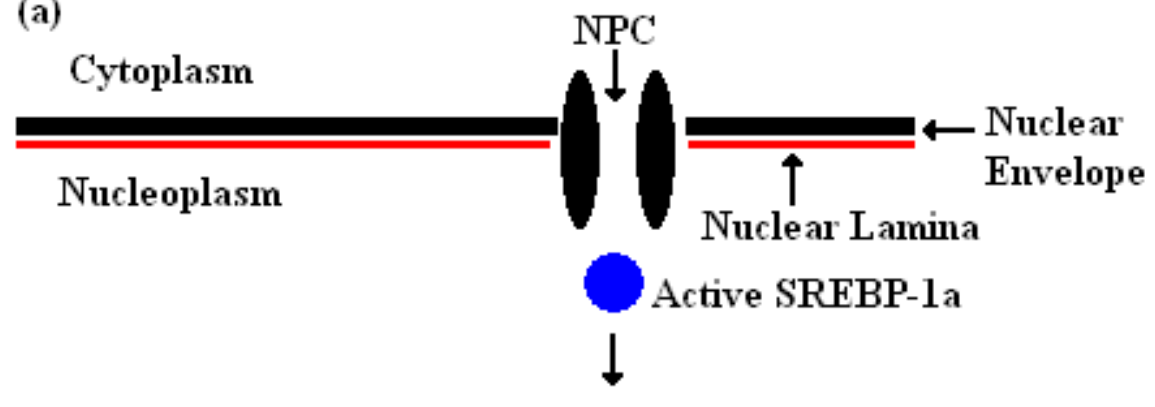

SREBP-1a target genes

activated

(b)

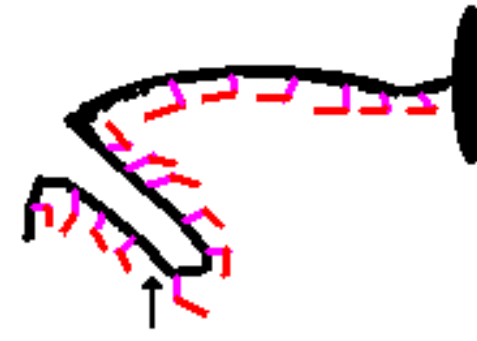

NR may develop due to additional strain on the nuclear envelope

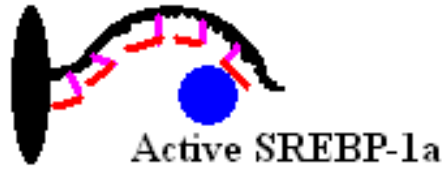

held at NE due to

retention of

c-terminus on lamin

A

SREBP-1 la target genes not activated 
Figure 2

(a)
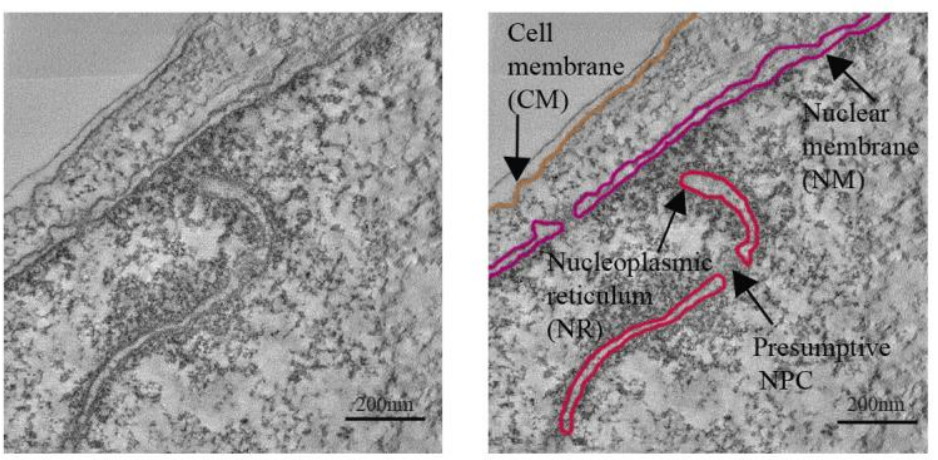

(b)
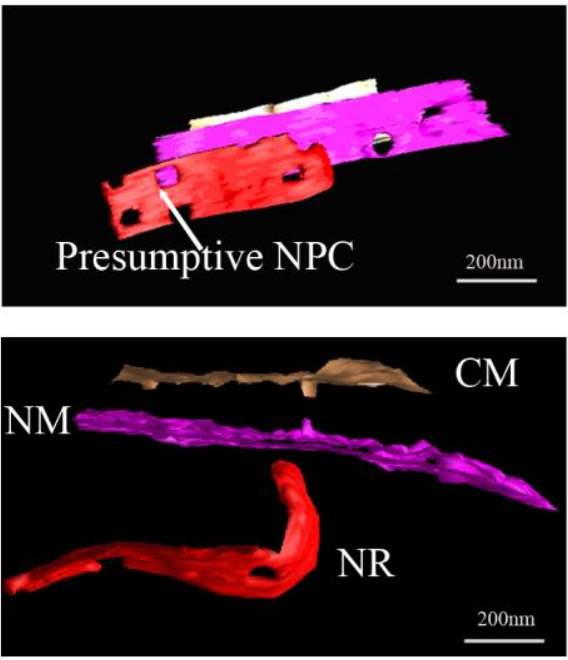